Artigo Científico Original

$$
\begin{aligned}
& \text { PARA UMA CONCEPÇÃ̄O } \\
& \text { PÓS-COLONIAL DO DIREITO DE ACESSO Á JUSTIÇA }
\end{aligned}
$$

Élida Lauris 


\section{PARA UMA CONCEPÇÃO \\ PÓS-COLONIAL DO \\ DIREITO DE ACESSO À \\ JUSTIÇA}

\section{TOWARDS A POST- \\ COLONIAL CONCEPTION \\ ON THE RIGHT TO ACCESS \\ TO JUSTICE'}

\section{Élida Lauris}

Doutora em Pós-colonialismos e Cidadania Global pelo Centro de Estudos Sociais e Faculdade de Economia, da Universidade de Coimbra. Foi investigadora do Observatório Permanente da Justiça Portuguesa do Centro de Estudos Sociais da Universidade de Coimbra. Actualmente é co-coordenadora do Projeto ALICE, onde desenvolve o projeto de investigação "Hérculeos juízes, cidadãos vulgares: estudo comparativo dos usos, do alcance e dos sentidos da transformação social escrita nas constituições da África do Sul e do Brasil". Sua tese de doutorado "Acesso para quem precisa, justiça para quem luta, direito para quem conhece. Dinâmicas de colonialidade e narra(alterna-)tivas do acesso à justiça no Brasil e em Portugal" foi distinguida com o Prémio CES para Jovens Cientistas Sociais de Língua Portuguesa em 2015. Tem experiência na área de Direito, com ênfase na sociologia do direito e dos tribunais e direito constitucional, actuando principalmente nos seguintes temas: acesso à justiça, independência judicial, reforma do judiciário, separação de poderes, judicialização da política, constitucionalismo e hermenêutica constitucional.

\section{RESUMO}

Uma releitura do acesso à justiça tem como primeiro desafio a denúncia do encerramento do debate sobre o acesso na simulação de uma tensão inexistente entre estrutura e ação em que esta última é sempre incorporada num processo de reforço e melhoria da primeira, o qual deve apoiar e pelo qual deve esperar. De um lado, vê-se a ação enquanto movimento implícito de mudança social que se dirige à expansão do papel das profissões e das estruturas jurídicas. De outro lado, o antagonismo criativo aos modos de funcionamento do direito e do Estado pela ação é simplificado como suplemento de participação no sistema jurídico, isto é, alternativas de acesso ao direito. Se não há lugar para a mudança radical da estrutura, o desvelar das ineficiências representam um eterno retorno da iniciativa de transformação à ação social. A revisão da compreensão de acesso à justiça requer, por isso, que se revisite as colaborações forjadas e as tensões ocultas

\section{ABSTRACT}

A rereading of access to justice has as first challenge the denouncement of the closure of the debate on access to simulate a non-existent tension between structure and agency as the latter is always incorporated into a process of strengthening and improving the first, which it should support and whereby it should expect. On the one hand, one sees agency as implicit movement for social change that addresses the expanding role of legal professions and structures. On the other hand, the creative antagonism to the modes of production of the law and the State by agency is simplified as a participation supplement in the legal system, i.e. alternatives to access to justice. If there is no place for a radical change of the structure, the unveiling of the inefficiencies represent an eternal return of the transformation initiative to agency. Accordingly, a reconsideration of the understanding of access to justice requires revisiting forged collaborations and hidden tensions in the relationship

Este artigo foi desenvolvido no âmbito do projeto de investigação "ALICE, espelhos estranhos, lições imprevistas", coordenado por Boaventura de Sousa Santos (alice. ces.uc.pt) no Centro de Estudos Sociais da Universidade de Coimbra - Portugal. O projeto recebe fundos do Conselho Europeu de Investigação, 7. Programa Quadro da União Europeia (FP/2007-2013) / ERC Grant Agreement n. [269807]. 
na relação entre Estado e sociedade civil no que toca às reformas de ampliação do acesso ao direito. Este artigo procura depurar a conceção compreensiva do acesso à justiça, submetendo-a ao crivo de uma análise crítica do lugar do Estado e da sociedade civil na construção de políticas de acesso à justiça nos estados democráticos pós-modernos.

Palavras-chave: acesso à justiça; assistência jurídica, Estado, Sociedade Civil, pós-colonialismos. between State and civil society with regard to access to law and justice legal reforms. This paper seeks to restore a comprehensive conception of access to justice, subjecting it to the scrutiny of a critical analysis of the role of the State and civil society in building access to justice policies in post-modern democratic states.

Keywords: access to justice; legal assistance, State, Civil Society, post-colonialisms.

\section{INTRODUÇÃO}

O acesso à justiça habitualmente traz consigo um conteúdo normativo acerca do sistema jurídico e da sua efetivação que extravasa a temporalidade e a contextualização da própria expressão. Como recorda Galanter (2010:1 15-116), a utilização do termo "acesso à justiça" para representar a ampliação da ação e das expectativas de busca de justiça em face do sistema jurídico, é recente, tendo surgido apenas no final da década de 1970. Esvanecido inicialmente na noção de assistência jurídica aos pobres ou como decorrência do princípio de igualdade perante a lei, 0 acesso à justiça enquanto expressão acompanha a popularidade do projeto Florença ${ }^{2}$, coordenado por Mauro Capelletti. É com a publicação do conjunto de artigos e da série acesso à justiça resultante do projeto Florença que se assiste à fixação do termo e à defesa de um conceito compreensivo que abarca uma progressiva diversificação judicial e

2 O projeto, financiado pela Fundação Ford, Ministério de Educação e Consetho Nacional de Pesquisa italianos, reuniu mais de uma centena de investigadore de diferentes áreas (direito, sociologia, ciência política, antropologia, psicologia) dedicando-se ao estudo do sistema de acesso em cerca de trinta países. Os resultados da investigação foram publicados em 1978/1979 em quatro volumes: Volume (Access to justice: A world survey, coordenado por Cappelletti e Garth); Volume II (Access to Justice: Studies of promising institutions, coordenado por Cappelletti e Weisner), Volume III (Access to Justice: Emerging perspectives and issues), Volume IV (Patterns in Conflict Management: Essays in the ethnography of law. Access to justice in an anthropological perspective, coordenado por Koch). Posteriormente foi publicado em 1981 o volume Access to Justice and Welfare State. não judicial, administrativa e não-governamental dos modos de entregar o direito. Daí que o próprio Cappelletti seja uma referência inultrapassável na elaboração de uma conceção ampla de acesso à justiça, nos seus próprios termos, um movimento composto no âmbito da metáfora de sucessivas ondas de reformas jurídicas tendo em vista a ampliação das oportunidades de acesso.

A principal contribuição desta formulação é a naturalização do acesso à justiça como inerente ao movimento de evolução dos estados democráticos ou de democratização de estados em evolução. Parece natural não só esperar que as medidas de acesso à justiça sejam amplas, como também manter grandes expectativas acerca da possibilidade de ampliar a democratização dos estados, das suas instituições e dos seus profissionais através do alargamento do acesso à justiça. Assim, a fórmula do acesso à justiça tem acomodado resultados tão diversificados quanto aparentemente contraditórios como:

1) $\bigcirc$ fortalecimento das instituições jurídicas e administrativas e das carreiras profissionais que integram e o reforço de medidas de accountability e participação social nestas instituições. 
2) A centralidade do direito do Estado como bem de providência social e medidas de relativização dos fundamentos epistemológicos desse mesmo direito - titularidade coletiva dos direitos, informalização da justiça, etc.

3) O reforço do papel das profissões na assistência jurídica e na entrega de um resultado social justo através do acesso ao direito, a crítica ao encastelamento dos profissionais e a defesa da desprofissionalização da justiça.

4) $O$ protagonismo do Estado na sua democratização, a ampliação da juridificação na vertente do acesso e o desvelar da violência da intervenção do Estado, da utilização ideológica do direito e da insuficiência do direito estatal na regulação das relações sociais.

Uma conceção ampla de acesso à justiça parece fadada à oscilação entre a transgressão da denúncia das limitações do universo jurídico e a grandiloquência da promessa de democratização do direito e através dele. As dificuldades em quebrar esse circuito têm evidenciado os mecanismos de acesso à justiça como essencialmente fraudulentos, noutras palavras, um esquema retributivo limitado que trai frequente e repetidamente as expectativas que cria (Abel, 1996).

Como pretendo defender neste artigo, persistem dois dilemas centrais no que toca à discussão atual do acesso à justiça. $\mathrm{O}$ primeiro dilema dá-se entre acesso e direito e pode ser assim formulado: como o acesso à justiça se pode manter como poderosíssima mensagem de igualdade pelo e do direito num contexto em que os modos de produção e reprodução do campo jurídico ${ }^{3}$ são evidências arrebatadoras da manutenção das desigualdades

\footnotetext{
3 Utilizo a expressão campo jurídico para referir ao espaço próprio de produção e reprodução do direito que, no contexto de afirmação tecnocrática da governamentalidade, se define como autónomo e exclusivo na medida da especialidade profissional que consagra e protege.
}

nas sociedades? Esse dilema tem deixado os estudos sociojurídicos do acesso à justiça numa encruzilhada entre o triunfalismo e o niilismo. Entre afirmar a promessa do acesso à justiça e criticar o défice epistemológico do direito e sua utilização ideológica para os fins de dominação política, não parece possível formular uma teoria crítica que evidencie a estrutural desigualdade como meio de realização do direito e simultaneamente enuncie o acesso à justiça como alternativa credível para a emancipação social. Neste caso, tratar-se-ia de acesso em condições desiguais ou acesso ao aparato de manutenção do status quo, enfim, acesso não à igualdade mas à desigualdade. Ao mesmo tempo, os grandes modelos de transformação social (socialismo e revolução) parecem esgotados e o reformismo não tem sustentado outro trânsito de mudança que não seja o do Estado que cura a própria incúria (Santos, 2006: capítulo 10). Daí ser natural a reflexão do acesso à justiça ter entrado numa espiral em que a celebração dos avanços na democratização do direito e o ceticismo em face da fragmentação do acesso num mercado de serviços jurídicos limitado fazem parte de um mesmo futuro que não poderá vir de outra direção que não do progresso do direito e do Estado. Esta espera pelo futuro, que se dá num cenário de recolha e coordenação de fragmentos, ficou desnudada de um sentido crítico, seja ele conservador ou progressista. Se os recursos são limitados e o futuro é um só, a construção de uma teoria crítica de acesso à justiça afigura-se inútil.

O segundo dilema diz respeito à relação entre tribunais e emancipação social: se os tribunais têm um papel de mudança social e a experiência de acesso e de conhecimento do direito é um privilégio de poucas/os, como pode ser emancipatória a mudança social enquanto experiência apenas daquelas/es que puderam 
acedê-la e/ou têm competência para enunciá-la? Questiona-se a afirmação do papel emancipatório dos tribunais e a utilização do direito no âmbito da mobilização de recursos da ação coletiva. A relação entre tribunais e emancipação social tem sido debatida no interior de uma ambiguidade estrutural, inerente ao próprio direito. Entre a fundação do direito como repressão e sua refundação como resistência, a expectativa em relação aos tribunais é dual: afirmar a cidadania, conservando a ordem das coisas, por um lado, e transformando-a, por outro. Como argumentarei neste artigo, os limites de uma análise institucionalista e o mito decorrente de uma leitura estrita das vitórias judiciais como vitórias de transformação social, se contextualizados no âmbito de uma abordagem constitutiva do direito, transfiguram a questão da centralidade da litigação para os projetos emancipatórios. Em vez de centralidade, indaga-se sobre a utilidade do recurso aos tribunais num universo em que a difusão do poder e das subjetividades exige uma leitura mais apurada acerca da política contenciosa e da micropolítica (Scott, 2000) da resistência.

Nos estados contemporâneos, a opção de acesso à justiça tem sido construída sob a vigilância, a hesitação e a suspeição dos estados e das classes dominantes. Trata-se de um processo cuja procura de soluções e alternativas de estabilização e recuperação das raízes do pensamento jurídico moderno transforma a expectativa de democratização dos estados numa espera prolongada e angustiante. Em primeiro lugar, como afirma Santos, o contrato social moderno é irreversível (Santos, 1998a), isto é, a adesão ao projeto político de dominação moderna é definitiva, não havendo hipótese de renúncia ou rescisão contratuais. Em segundo lugar, o processo de emenda e ajuste dos termos contratuais, se está destinado a conservar as raízes ${ }^{4}$, não pode explorar a radicalidade das opções. As soluções de acesso à justiça ficam assim recolhidas no interior de uma abordagem estrutural-funcionalista. Nesse sentido: (1) a experiência de acesso é conformada pelos padrões de funcionamento das estruturas jurídicas; (2) a falta de acesso à justiça corresponde a obstáculos estruturais vivenciados pelos cidadãos; (3) a resposta aos obstáculos de acesso subsume-se a tentativas de coordenação de diferentes iniciativas/alternativas de acesso à justiça. No âmbito desta abordagem, que em muito colaborou para visibilizar a responsabilidade do Estado no que toca à promoção do acesso à justiça, a produção de uma teoria do direito crítica é um contrassenso. Apesar de demonstrar empiricamente a disparidade entre princípios e práticas no âmbito da realização do acesso à justiça pelas instituições estatais, a estrutura é simultaneamente um problema e uma solução. A abordagem estrutural-funcionalista faz assim uma crítica empírico-metodológica, e nunca epistemológica ou fenomenológica, à evidência de produção e reprodução das desigualdades pelo direito.

Uma releitura do acesso à justiça tem como primeiro desafio a denúncia do encerramento do debate sobre o acesso na simulação de uma tensão inexistente entre estrutura e ação em que esta última é sempre incorporada num processo de reforço e melhoria da primeira, o qual deve apoiar e pelo qual deve esperar. De um lado, vê-se a ação enquanto movimento implícito de mudança social que

\footnotetext{
Santos (1998) distingue o pensamento social como um pensamento dualista entre raízes e opções, as características distintivas entre o modo de pensar moderno e o tradicional residiria no facto de a modernidade fundar raízes a partir das quais se deriva um conjunto de opções. Enquanto as sociedades tradicionais são sociedades de raízes (a religião, os costumes), as sociedades modernas caracterizam-se por ter à disposição um conjunto vasto de opções. Ao radicalizar a razão como fundamento último da vida social e coletiva, a racionalidade moderna distingue-se pela possibilidade de radicalização e proliferação das opções a partir de um universo fundacional que estabelece como universal, objetivo e secular. $O$ dualismo entre raízes e opções nos termos propostos por Santos é especialmente útil para a discussão da relação entre acesso, direito, justiça e Estado.
} 
se dirige à expansão do papel das profissões e das estruturas jurídicas. De outro lado, o antagonismo criativo aos modos de funcionamento do direito e do Estado pela ação é simplificado como suplemento de participação no sistema jurídico, isto é, alternativas de acesso ao direito. Se não há lugar para a mudança radical da estrutura, o desvelar das ineficiências representam um eterno retorno da iniciativa de transformação à ação social. A revisão da compreensão de acesso à justiça requer, por isso, que se revisite as colaborações forjadas e as tensões ocultas na relação entre Estado e sociedade civil no que toca às reformas de ampliação do acesso ao direito. Na sua parte final, este artigo procura depurar a conceção compreensiva do acesso à justiça, submetendo-a ao crivo de uma análise crítica do lugar do Estado e da sociedade civil na construção de políticas de acesso à justiça nos estados democráticos pós-modernos.

\section{SER OU NÃO SER: ACESSO À JUSTIÇA, TRIBUNAIS E EMANCIPAÇÃO SOCIAL}

A reflexão sociojurídica acerca do acesso à justiça tem ocupado um lugar de espera pela vontade política, uma espera que preenche afirmando a necessidade de acesso, ora demonstrando os seus fracassos, ora oferecendo propostas para o seu êxito. No entanto, a esperança de sair da posição de expectador da vontade política e tornar-se parte do processo de decisão do sistema de governo tem sido confiada à possibilidade de acesso à justiça. Aposta-se na mobilização das agências governamentais e do judiciário para, colocando em pauta a efetivação de direitos, questionar os rumos do sistema jurídico e as escolhas da política pública. Neste caso, espera-se o acesso para não ter que esperar mais. Esta relação entre esperanças e expectativas no âmbito do acesso à justiça é complexa, a dupla esperança é também dupla dependência: a esperança a depender das oportunidades de acesso, as expectativas a dependerem da lógica operativa das instituições. A equação entre esperanças e expectativas não pode ser resolvida no domínio da administração rotinizada dos conflitos pelo sistema jurídico, requerendo que $\circ$ foco de análise se estenda para além da mecânica de funcionamento do Estado, noutras palavras, implica o debate da justiça como instituição política.

A discussão do acesso à justiça sofre, assim, um afunilamento do seu alcance compreensivo para dedicar-se à discussão dos limites e das possibilidades de realização da emancipação social pelos tribunais. Como afirma Santos, a decisão sobre a partilha de direitos, em regra, contrapõe interesses sociais divergentes (empregadores versus trabalhadores, consumidores versus produtores, homens versus mulheres, cidadão versus Estado, etc.). Logo, a reivindicação de uma solução jurídica sobre a titularidade do direito, muito embora aparente ser uma solução meramente técnica, pode assumir um forte conteúdo de mudança do status quo social e político (Santos, 1986). Devido às suas potencialidades no âmbito da transformação e justiça social, o conceito de acesso à justiça deve desenvolver-se num quadro conceptual amplo de articulação entre agência e estrutura na distribuição dos direitos, o que inclui a mobilização de procedimentos e mecanismos judiciais (representação em juízo, consulta jurídica, defesa adequada, devido processo legal), instituições estatais não judiciais (administração pública) e instituições não estatais (partidos políticos, organizações não-governamentais) através da iniciativa de cidadãos, empresas e grupos sociais, circunscrevendo não só conflitos individuais, mas também questões coletivas e de direitos difusos, com especial atenção 
aos conflitos estruturais e às clivagens socioeconómicas existentes (género, classe, etnicidade, etc.). Contudo, no campo da disputa pela distribuição dos recursos políticos, dado o papel dos tribunais enquanto órgão de soberania dedicado à aplicação e à garantia dos direitos em última instância, o acesso à justiça strictu sensu, isto é, o acesso ao poder judiciário, assume a centralidade da discussão.

Neste domínio, emergem as contribuições da análise institucionalista do judiciário. A abordagem institucionalista, ao propor levar as estruturas a sério, deixa de lado leituras behaviouristas do funcionamento dos tribunais, substituindo a atenção que se dá à atitude dos profissionais como ponto irradiador do posicionamento político dos tribunais pela atenção à instituição tribunal. $\bigcirc$ judiciário é, assim, contextualizado no interior do sistema político como mais uma das suas instituições ${ }^{5}$ (Shapiro, 1964). Esta contextualização traz consigo uma necessidade de reenquadramento do papel dos tribunais pelo menos em três aspetos, como argumentam Gisburg e Kagan (2005: 3). Em primeiro lugar, reconhece-se que o judiciário exerce poder, aliás, como qualquer outra instituição ou órgão do Estado. As decisões judiciais não se limitam a ditar o destino de litigantes individuais, elas fazem política e afetam o comportamento de agentes governamentais, empresas e grupos de cidadãos. Consequentemente, também os tribunais se submetem a um contexto de legitimação constante, procurando mais consenso e apoio do que oposição e resistência. Esta busca por legitimidade, por sua vez, circunscreve as possibilidades de

\footnotetext{
5 A discussão do judiciário como instituição política ganhou popularidade com a ideia de expansão global do poder judiciário e judicialização da política, pioneiramente formuladas por Tate e Valinder (1995). Em linhas gerais, Tate e Valinder delimitam a ideia de judicialização como um processo de generalização da forma do processo judicial, o que pode implicar tanto o deslocamento do processo de decisão acerca de direitos do legislativo e das agências do executivo para os tribunais, quanto o extravasamento do modo de adjudicação para fora do lugar que lhe é próprio, o judiciário. Sobre o tema, ver, Shapiro e Stone Sweet, 2002 Trochev, 2004; Guarnieri e Pederzolli, 2002; Sweet, 2000, Epstein e Knight, 1996 e Hirschl, 2004.
}

ação dos tribunais tal e qual ocorre com os poderes executivo e legislativo.

Em segundo lugar, os tribunais interagem num processo dinâmico com outros órgãos do governo submetendo-se igualmente à pressão externa de ideias, ideologias e políticas, o que significa dizer que não basta compreender a ideologia que compromete a ação individual de juízes sem entender o fluxo de interação ideológica entre tribunais e academia, media, grupos sociais organizados e outras instituições políticas. Neste contexto, é evidente que as decisões judiciais são tão influenciadas por princípios quanto pelos limites do que é politicamente possível. Os limites da política possível requerem atenção a prováveis retaliações ou estratégias dos órgãos e agentes políticos que podem contornar a eficácia das sentenças judiciais ou recusar a sua aplicação. Em terceiro lugar, os tribunais exercem influência nos rumos do sistema político e têm autoridade no debate público. Daí que a forma como os tribunais são organizados e geridos, o controlo hierárquico e disciplinar do campo comunicativo, as imposições deontológicas e a defesa da neutralidade do juiz influenciam o impacto discursivo dos tribunais na política. Como se vê, do ponto de vista da relação entre direito e emancipação social, a abordagem institucionalista aponta mais limitações do que vantagens ${ }^{6}$ para 0 exercício de uma função transformadora pelos tribunais.

O campo de debate acerca do potencial de transformação dos tribunais tem sido, assim, clivado pelo confronto entre confiança institucional e defraudação das expectativas ${ }^{7}$. A adoção de um dos dois

\footnotetext{
6 Como afirmou Santos (2011: 14): Ante os desafios e dilemas do acesso ao direito, do garantismo de direitos, do controlo da legalidade, da luta contra a corrupção e das tensões entre a justiça e a política, os tribunais foram mais vezes parte do problema do que parte da solução.

7 A discussão sobre limites e possibilidades do direito no que toca à emancipação social acompanha as clivagens e divergências levantadas pelo movimento de Critical Legal Studies.
} 
polos é variável de acordo com a possibilidade de a ação do poder judiciário conseguir extravasar a camisa de força da sua posição institucional. Demostrando os apertados limites institucionais do judiciário, Rosenberg (2008) narra a experiência de transformação social pelos tribunais como uma experiência de emancipação regulada. Desde logo indica a necessidade de apoio para que os tribunais possam fazer frente às tentativas de ludibriar a aplicação das decisões judiciais por parte dos outros poderes políticos. Por outro lado, a ineficácia da mudança social decidida pelos tribunais evidencia-se na dependência judicial face a poderes de implementação que competem a outros órgãos, o que, no fundo, decorre de a arquitetura política dos estados modernos liberais se ter encarregado de criar um poder judiciário sem poderes.

Ao analisar a experiência americana, Rosenberg exemplifica essas limitações ao referir as barreiras políticas levantadas por muitos líderes políticos norte-americanos para a implementação do direito de aborto, bem como a necessidade de intervenção do governo federal para se garantir as decisões judiciais conquistadas pelo movimento de direitos civis. Neste quadro, adverte primeiramente para o que considera ser um desperdício financeiro, de talentos e de recursos críticos, apostar numa alternativa de mobilização cujo resultado pode ser o enfraquecimento político da causa. As vitórias judiciais simbólicas seriam responsáveis por conduzir ao erro estratégico de celebração de uma ilusão que encobre uma realidade desencantada, desviando a atenção das forças sociais do caminho de transformação desta realidade. A concentração de esforços na judicialização, neste sentido, acaba demovendo a utilização de outros meios de reivindicação que poderiam ser mais efetivos e menos comprometedores dos recursos disponí- veis. Por fim, adverte para $\circ$ efeito de contra-mobilização que acompanha a judicialização de casos controversos. Se uma das vantagens imediatas do recurso aos tribunais é a maior popularidade dos casos, o outro lado desse movimento é a mobilização dos oponentes da causa. Muito embora os dois lados já existam antes do recurso ao tribunal, as posições fortalecem-se na batalha judicial e um dos resultados negativos da falta de eficácia da ação judicial é o fortalecimento de quem se opõe à causa.

A maior vantagem da abordagem institucionalista é o facto de afirmar o judiciário como poder político a par da contextualização dos seus limites. Nesse sentido, descortina o facto de que muitas das tentativas de utilizar a judicialização como concretização da imagem do Estado como centro da promoção de direitos tem servido para construir o que a literatura sociojurídica denomina o mito dos direitos. $\mathrm{O}$ mito dos direitos reforça a centralidade do Estado e do seu direito, apostando no papel a ser desempenhado pelos tribunais como instância última da proteção dos indivíduos e da probidade da política. Trata-se de um raciocínio especialmente sedutor pela linearidade que estabelece entre o papel de ativistas, profissionais do direito, tribunais e mudança social. Conforme formulado por Scheingold (2007), o mito dos direitos sucumbe primeiramente ao não reconhecer a distância entre a enunciação de um direito no ordenamento jurídico e a sua efetiva garantia. Acreditando ingenuamente que essa distância pode ser percorrida nos tribunais, profissionais do direito tendem a investir na litigação como se a mudança social fosse decorrer de uma estratégia de tentativa e erro junto dos tribunais, ignorando, assim, o possível efeito despolitizador da tramitação de uma demanda social e política quando convertida em conflito jurídico entre duas 
partes e, consequentemente, investindo em estratégias de litigação que consomem os recursos do que poderia integrar uma estratégia coordenada de manobras políticas de maior impacto. A realização dos direitos a partir da garantia judicial torna-se, assim, um concurso de vontades e de recursos entre as partes envolvidas.

Com base nesses argumentos, Scheingold (2007) sugere a substituição da centralidade da litigação pela utilidade da litigação, e do mito de direitos por uma política de direitos. Esses dois polos - centralidade/utilidade dos tribunais, mito/ política de direitos - têm dividido a reflexão acadêmica acerca da relação entre ativismo social, direitos e papel dos tribunais. A própria relação entre a teoria dos movimentos sociais e a sociologia da política de direitos manifesta a oscilação entre $o$ deslocamento centro-periferia do papel da litigação e do direito. Se é certo que a teoria dos movimentos sociais tem dado uma atenção marginal ao papel do direito, enquadrado como recurso no âmbito da análise organizacional dos movimentos, não é menos verdade que a sociologia e a teoria do direito dedicam-se aos resultados das instituições jurídicas na defesa do/s direito/s como se não existisse uma agência exterior a estas instituições. Este estranhamento tem sido ultrapassado aos poucos através da análise de categorias híbridas às duas reflexões disciplinares, como mobilização do direito ${ }^{8}$ ou advogados de causas ${ }^{9}$, que circulam na fronteira entre estrutura e ação jurídicas. Neste ponto, a abordagem institucionalista e positivista é abandonada em nome de uma abordagem constitutiva do direito.

A abordagem constitutiva do direito interessa-se pelos meios através dos quais os

8 Para um conceito de mobilização do direito interdisciplinar, ver Mccan, 2006 Para uma abordagem unidisciplinar da mobilização do direito, ver Black, 1973.

9 Ver Sarat e Scheingold, 1998, 2001 e 2005. processos jurídicos constituem a realidade social e são constituídos por ela. Trata-se de uma visão ampla do campo jurídico e do seu significado cultural, das formas como o papel do direito é culturalmente produzido e como produz significados culturais e identidades. Nos termos de Merry (1994) a abordagem culturalista do direito implicou deixar de lado o domínio da investigação empírica da resolução de conflitos, já tomado como certo, e aventurar-se por domínios, como os direitos humanos ou as narrativas nos tribunais, em que categorias como a contexto, identidade e interseccionalidade são centrais às preocupações metodológicas. A sociologia interpretativa do poder cultural do direito devolve uma abordagem compreensiva ao acesso à justiça para explorar a relação entre direito e emancipação social. Recusando a imagem do Estado como centro do/s direito/s, a principal contribuição dessa abordagem é de-centrar o direito. Mais do que falar do Estado ou falar para o Estado, vê-se o fenómeno do poder e do direito espraiar-se em domínios que extrapolam a esfera do Estado, questionando a univocidade do seu contraponto, a sociedade civil. É neste âmbito que Santos (2002a: 243303) defende a necessidade de uma conceção pós-moderna de direito que deve compreender a interlegalidade inerente à manifestação do poder jurídico e disciplinar em distintas unidades de práticas sociais como o sexismo, o racismo, o produtivismo, o consumismo. Numa conceção pós-moderna do direito, o Estado é apenas um dos domínios de interlegalidade, o domínio da cidadania.

No âmbito de uma abordagem constitutiva do direito, reescreve-se a relação entre tribunais e emancipação social. A abordagem positivista e institucionalista reforça a imagem do Estado como centro, afirmando a essencialidade dos tribunais na redistribuição dos recursos políticos 
em conflito, o que traz à tona a questão sobre $\circ$ que os tribunais podem fazer pela emancipação social. Esta pergunta, por sua vez, tem uma resposta manifesta, em face dos seus limites institucionais, os tribunais, por si, pouco ou nada podem fazer. Assim, sem abrir mão da análise do Estado como esfera da cidadania, o vasto espaço de não-concretização da centralidade do Estado é um espaço de investigação das formas que podem ser assumidas pela produção e reprodução do poder, do direito e da resistência. $O$ recurso aos tribunais é apenas uma das formas de reprodução possível do direito, o que inverte os termos da pergunta sobre a utilidade dos tribunais. Uma abordagem interpretativa indaga $\circ$ que as narrativas de resistência e produção do direito fora do centro podem fazer pelos/com os tribunais, bem como com outras agências do Estado, uma vez que ampliam o campo de visão sobre as formas de poder e os modos do direito, questionando a sua unidade discursiva através da resistência.

A abordagem constitutiva do direito e a sociologia interpretativa adequam-se às possibilidades de discussão da política e do direito num mundo pós-moderno. Trata-se de um mundo fracionado pelos nacionalismos, racismos, machismos, destruição ambiental, etc. Neste mundo, que não comporta a solução de uma subjetividade unívoca (o indivíduo) ou de macrossubjectividades de síntese ou antítese dialética (o Estado, o partido, o proletariado), a análise do direito é mais desconstrutiva, do que construtiva, não sendo claro qual o caminho a ser seguido pela teoria social do direito para manter o seu compromisso com a emancipação e a justiça social. Handler (1992) apresenta este dilema densificando-o no que toca à composição e à agenda dos novos movimentos sociais. Os novos movimentos sociais, que podem ser considerados os arquétipos da política pós-moderna, advogam uma nova forma de fazer política (baseada na ação direta, processos de decisão participativos, estruturas descentralizadas), defendem maior atenção ao cultural e às questões relativas à qualidade de vida, apelam por maiores possibilidades de participação nas decisões políticas e estão determinados a lutar por uma vida melhor, sem, contudo, pré- determinar os planos para uma sociedade melhor. Como criticam os padrões de racionalidade institucionalizada da modernidade, rejeitam um desenho institucional ou uma visão compreensiva para uma nova sociedade. As questões, reivindicações e demandas que levantam não referem a uma visão ou força unificada, por isso, as pontes de diálogo com racionalidades de transformação social totalizantes, como o marxismo ou liberalismo, são estreitas, o que significa defender a transformação social sem uma teoria geral para sustentá-la.

No que toca à discussão sobre o acesso à justiça, movemo-nos de um terreno seguro, a defesa de um movimento universal de acesso à justiça que tem como protagonista $\circ$ Estado e as profissões jurídicas e como principais favorecidos, os cidadãos e cidadãs, beneficiárias/os diretas/os da construção de uma sociedade justa e igualitária, para um domínio de desconstrução do direito como narrativa emancipatória. Este mundo pós-foucaltiano deixa a descoberto teorias universalistas da igualdade, desestabilizando a autoridade do direito e do raciocínio jurídico com contra-narrativas de opressão e disciplina, levadas a cabo por uma microssociologia do poder. Este é o mesmo lugar em que as dinâmicas de falta de reconhecimento e de injustiça distributiva aproximam desigualdade e exclusão (Santos, 1999).

Como argumenta Santos (1999), cada vez mais a subordinação de classe cria 
interditos culturais que negam o reconhecimento a quem não está integrada/o no setor produtivo (desempregados, trabalhadoras domésticas, moradoras e moradores de rua), bem como os critérios de interdição do reconhecimento multiplicam a diferenciação na distribuição de recursos às/aos desiguais (aumento na diferenciação no trabalho entre homens e mulheres, brancos e negros, etc). As micronarrativas de opressão, nesse sentido, não podem abrir mão da crítica e da luta macroestrutural por igualdade e reconhecimento de direitos. Esse contexto parece forçar a discussão sobre o acesso à justiça a optar entre a desconstrução da autoridade e do poder do direito e a construção de uma política macroestrutural de redistribuição e reconhecimento de direitos. Noutras palavras, a discussão do acesso à justiça ou celebra o presente pelo que nele há de pós-moderno ou celebra o que há de moderno no presente.

Na minha conceção, uma teoria crítica pós-colonial do acesso à justiça ${ }^{10}$ assenta em três momentos de consciência: uma consciência epistemológica, uma consciência política e uma consciência pragmática. A consciência epistemológica desconstrói a autonomia e autoridade do conhecimento jurídico científico evidenciando o juricídio (Santos, 2007b: 29-81) que comporta e o seu papel ideológico na naturalização do discurso da dominação política. No âmbito da entre desigualdade e exclusão, reconhece ainda o papel da autoridade do discurso jurídico na interdição do reconhecimento através de um universalismo anti-diferencialista e da integração subordinada das/os desiguais na dinâmica de gestão da exclusão e da inclusão feita pelo contrato social moderno (Santos, 1999).

10 A crítica pós-colonial do direito e do acesso à justiça que aqui delineio segue de perto a crítica ao papel da história e seus protagonistas conforme formulada pelos Subaltern Studies. Ver Chakrabarty, 2000 e Guha, 2002.
A consciência política descentra o poder e o direito do Estado, esse descentramento está ao serviço tanto da democratização do poder, evidenciando esferas de opressão que foram afastadas da esfera pública de liberdades e de direitos, quanto do reconhecimento da resistência, que aceita o nominalismo dos direitos e das liberdades instituídos pelo Estado mas recusa a exclusividade do seu regime de verdade (Foucault, 1999). Aposta-se numa construção do direito através do diálogo entre as diferentes experiências de poder, opressão e conquista de direitos. A consciência pragmática assenta-se na evidência de duas impossibilidades, a impossibilidade de se construir uma teoria geral de emancipação social ${ }^{11}$ através do direito e a impossibilidade de se renegar a política de direitos do Estado. Ainda que o discurso liberal e social de direitos integre um regime epistemológico de interdição e um regime político de dominação e gestão da exclusão e inclusão, a perda de fé nos direitos só gera consequências danosas para os interditos do direito, cuja aposta na linguagem dos direitos pode atuar como motor para a refundação do seu valor nas sociedades. Assim, a luta por acesso à justiça afirma-se como um processo de tradução entre a afirmação dominante dos direitos, a afirmação da opressão, das várias manifestações do poder e da denegação dos direitos, a repetição e a contra-afirmação dos direitos pelas/os dominadas/os. Formulada nestes termos a teoria crítica do acesso à justiça dirige-se à reformulação das categorias sociedade civil e Estado.

\section{Sociedade Civil}

O enquadramento da sociedade civil no âmbito da discussão do acesso à justiça

Santos $2002 \mathrm{~b}$ argumenta impossibilidade hodierna de se produzir uma teoria geral da emancipação social, defendendo por isso uma sociologia das ausências e das emergências. 
tem uma história linear que acompanha a evolução do seu contraponto, o Estado. Como atesta a ideia de movimento global de acesso à justiça, pode-se dizer que à sociedade civil sempre coube um papel secundário, limitado à função passiva de utente da evolução do Estado, este sim, protagonista da reforma social dedicada à evolução do acesso à justiça. Assim, a sociedade civil beneficiária da política pública de acesso à justiça veio corresponder aos modos de funcionamento de um Estado-providência especialmente em face da previsão de direitos económicos e sociais a serem reivindicados contra o Estado. No mesmo sentido, nos marcos de um Estado liberal, instaura-se uma política de acesso à justiça reparatória, em que as distorções na igualdade de representação processual são restauradas pela ação filantrópica dos profissionais do direito.

Com a crise do Estado-providência esta relação foi alterada, emergindo a sociedade civil panaceia dos males do acesso à justiça e da fraqueza do Estado. A sociedade civil panaceia pode assumir três sentidos (Comaroff e Comaroff, 2006):

1) A sociedade civil contra $\circ$ Estado, onde as questões relativas ao acesso à justiça são resolvidas pela autorregulação das partes.

2) A sociedade civil de soluções privadas, celebrada como alternativa econômica e eficaz de oferta de serviços jurídicos.

3) A sociedade civil comunidade, como organização, agente ou ação coletiva que partilha os custos e as responsabilidades da governação' ${ }^{12}$.

É curioso notar a recuperação da dicotomia Estado-sociedade civil em face do reconhecido falhanço da categoria so-

12 No Brasil, a capacitação da comunidade tem recebido atenção de programas de acesso à justiça financiados pelo Estado. Ver Secretaria de Reforma do Judiciário, 2006 e 2008. ciedade civil na realização da promessa moderna de igualdade. A teorização crítica do acesso à justiça fica a padecer diante deste facto: a evidência da insuficiência da dicotomia Estado-sociedade civil não foi acompanhada da problematização da categoria sociedade civil como esfera de realização dos direitos e das liberdades. Assim, a sociedade civil foi reerguida como solução para o problema da falta de acesso à justiça, num contexto em que a construção da própria categoria sociedade civil é um exemplo inegável da histórica denegação de justiça na distribuição dos recursos políticos do Estado moderno. No âmbito de um consenso hegemónico neoliberal que assevera a existência de um Estado fraco (Santos, 2007b), o seu contraponto, a sociedade civil, ganha força e destaque.

Enquanto categoria clivada de tensões, a dicotomia Estado-sociedade civil tem resistido como os polos opostos de uma equação de liberdade e igualdade quando: (1) livres e iguais nunca foram atributos estendidos a todos e a todas; e (2) a própria ideia de liberdade das transações individuais sempre esteve dependente de alguma regulação econômica e social por parte do Estado. Contudo, a definição de uma oposição em que o Estado é a outra face da sociedade civil tem sido utilizada para asseverar que o fortalecimento da sociedade civil não se pode realizar noutro caminho que não o do enfraquecimento do Estado, e vice-versa. Esta relação, contudo, não atenta para o facto de que, como alerta Santos, a produção de uma sociedade civil forte depende da força do Estado para legalizar e deslegalizar a sua fraqueza (Santos, 2007b: 454-508).

Segundo esta lógica que representa a partilha e a transferência de responsabilidades do Estado na relação com a sociedade civil, Santo alerta para o facto de 
que a força da sociedade civil tem ocultado a expansão do Estado em forma de sociedade civil, com a criação de governos indiretos, paraestatais e, ainda, com a reprodução deliberada pelo Estado de sociedades civis, sociedades civis secundárias ${ }^{13}$, como denominou (Santos, 1990). Esta estatização da sociedade civil ou liberalização da esfera do Estado, por sua vez, é feita sem o espartilho da defesa da igualdade e da proteção contra a arbitrariedade do poder que orienta a dicotomia liberal clássica Estado-sociedade civil. No âmbito da discussão sobre acesso à justiça, a sociedade civil como panaceia da falta de acesso tem reproduzido sobre a dicotomia uma dupla invisibilidade: (1) a invisibilidade da manutenção da burocracia e da violência ${ }^{14}$ nos domínios de reprodução da justiça através da ou com a participação da sociedade civil, (2) a invisibilidade da participação social nos domínios profissionais exclusivos do sistema de justiça.

O carácter problemático da sociedade civil como solução no âmbito do acesso à justiça emerge da dinâmica entre divisões visíveis, divisões invisíveis e divisões abissais $^{15}$ (Santos, 2007a) que a categoria binária estado-sociedade civil provoca. A divisão visível é a própria dicotomia entre sociedade civil e Estado, esta distinção sobressai-se pela maleabilidade com que se adequa às dinâmicas de expansão e retração de cada um daqueles dois polos, assegurando que as metamorfoses do Estado sejam sempre consideradas democráticas desde que compreendam a

13 Ao conceituar a sociedade civil secundária, Santos dá o exemplo da utilização da capacidade reguladora do Estado para criar, no âmbito da privatização do Serviço Nacional de Saúde, espaços de atividade económica e empresarial privada, promovendo o associativismo corporativo, associando o capital privado ao sector público e incorporando áreas altamente lucrativas. (Santos, 1990)

14 Em Santos 2007 b, a burocracia, a violência e a retórica são apresentadas como elementos estruturais do direito.

15 De acordo com Santos (2007a) é inerente ao pensamento social moderno tanto o estabelecimento de divisões visiveis quanto a invisibilidade de divisões abissais. A linha abissal, que separa a racionalidade de dois modos de vida e reprodução das relações sociais, regulação/emancipação e violência/apropriação, distingue dois universos referenciais que não existem em simultâneo, a presença de um lado da linha torna o outro lado inexistente. separação entre uma esfera pública de poder e uma esfera privada de direitos. A clareza desta distinção tem a vantagem de estabelecer com nitidez o lado da política e do direito e o lado da cidadania, uma límpida separação em que esta última decorre da vocação anti-diferencialista e de justiça social dos dois primeiros, relação cujos traços evolutivos foram tão bem retratados por Marshall (1964). O Estado populista, o Estado interventor, o Estado-providência, a sociedade civil individualista, a sociedade civil comunitária, a sociedade de classes, apesar das diferenças entre e elas e na inter-relação com Estado, estiveram sempre incorporadas numa síntese dicotómica (estado versus sociedade civil).

A hipervisibilidade da dicotomia Estado e sociedade civil ofuscou a discussão em torno de outras distinções dentro de cada um destes extremos. A invisibilidade das distinções na sociedade civil foi definitivamente colocada em causa com a emergência das subjetividades pós-modernas. A sociedade civil fragmentada, por sua vez, fraciona a cidadania, afirmando que a justiça para ser social tem que ser, ao mesmo tempo, igualitária e diferencialista. Este movimento anti-totalizante de visibilização das distinções deixou, contudo, esquecida a permanência de divisões totais invisíveis no interior da sociedade civil, divisões abissais, nos termos de Santos (2007a). A meu ver, é nas divisões visíveis, invisíveis e abissais, que sustentam - jogo relacional entre sociedade civil e Estado, que deve residir uma noção compreensiva de acesso à justiça.

Na discussão feita até aqui, a conceção compreensiva do acesso à justiça é clara. Nos termos em que formulei no início deste capítulo, trata-se de uma progressiva diversificação judicial e não judicial, administrativa e não-governamental dos modos de entregar o direito. Pronunciado 
no âmbito de um movimento global e evolutivo do acesso à justiça pode-se dizer que a visão compreensiva, se não esteve atenta à emergência das subjetividades, soube reconhecer a existência de uma sociedade civil estratificada, que seria atacada por oportunidades de acesso à justiça progressivamente mais abrangentes. Mesmo não recorrendo aos mesmos termos, há o reconhecimento da existência de uma sociedade civil íntima (com indivíduos e grupos super-incluídos), de uma sociedade civil estranha (com indivíduos e grupos moderadamente incluídos e excluídos) e de uma sociedade civil incivil (indivíduos super-excluídos) (Santos, 2003) ${ }^{16}$, sendo contra essa estratificação que a ampliação do acesso à justiça atuaria. É seguro afirmar que, no período de prosperidade do acesso à justiça nos países centrais, as oportunidades criadas atingiram transversalmente todos aqueles estratos da sociedade civil. É esse o ideal que alimenta a associação do acesso à justiça como indicador da qualidade da democracia nas sociedades contemporâneas.

Contudo, o que a realidade de incumprimento ou cumprimento fragmentado da realização do acesso à justiça com a qual vivemos indica é uma tentativa de promoção da igualdade que, quando bem-sucedida, alcança no máximo a sociedade civil estranha. Trata-se da administração, em regra, de uma justiça anti-diferencialista e sobrecarregada, estancada na solução rotinizada de conflitos individuais. A realidade do acesso à justiça aponta para uma dinâmica de não acesso que reproduz uma divisão abissal entre a experiência da justiça e a experiência da opressão. A experiência da justiça corresponde a uma cidadania, em regra, individualista liberal,

16 Neste ponto acompanho a definição tripartite de sociedade civil apresentada por Santos, 2003: sociedade civil estranha, incivil e íntima. enquanto a experiência da opressão integra a imagem do Estado disciplinador e repressivo como centro. É a linha abissal (Santos, 2007a) entre justiça como cidadania e justiça como violência que explica o fenômeno popularmente conhecido como acesso à justiça pela porta dos fundos, isto é, o acesso à justiça da sociedade civil incivil é a justiça criminal.

A experiência de acesso enquanto oportunidade de apreciação rotineira do conflito individual, de um lado, é apresentada retoricamente como um momento de cidadania, de encontro entre o Estado e a sociedade civil, de outro lado, reproduz divisões já visíveis, não atendendo à necessidade simultânea da igualdade e da diferença na administração da justiça, tampouco às demandas de democracia participativa nos processos de decisão dos tribunais. As dificuldades de adequação e organização do judiciário à legislação de violência doméstica, legislação anti-racista é um bom exemplo desta realidade. O sistemático não acesso à justiça, por sua vez, resulta de uma divisão total entre a repressão e a promoção do direito. Esta distinção é comumente apagada nas discussões de acesso à justiça uma vez que a defesa de um movimento progressivo de alargamento do acesso negaria a sua própria formulação se reconhecesse que a dinâmica de acesso é também responsável pela reprodução da violência e exclusão. É, por essa razão, que defendo a reformulação do carácter compreensivo do acesso à justiça.

O primeiro passo de compreensão deve dirigir-se às divisões invisíveis e abissais produzidas pelo direito e pelo funcionamento dos mecanismos de acesso. É a partir desse reconhecimento que se deve projetar o alargamento da política pública e, não o contrário, promover - alargamento da política pública sem o respetivo reconhecimento das dinâmicas 
de desigualdade e exclusão que the são inerentes. $O$ reconhecimento das divisões é intensivo, implica conhecer as dinâmicas de exclusão extrema que, no âmbito da sociedade civil incivil e do lado da linha da justiça como violência, são os obstáculos ao acesso à justiça. Essa mudança de perspetiva não só assumirá o direcionamento da política de acesso ao domínio da sociedade civil incivil como imporá o acesso à justiça como uma dinâmica de co-presença radical ${ }^{17}$ (Santos, 2007a): às manifestações de violência e apropriação ilegítimas, perpetradas por ação ou omissão do Estado, devem corresponder uma presença da defesa contra a arbitrariedade e da promoção de direitos.

\section{Estado}

A relação entre Estado, direito e acesso à justiça tem sido enquadrada numa abordagem estruturalista. A experiência de acesso enquanto conformada aos padrões de funcionamento das estruturas jurídicas implica uma forma peculiar de contar o acesso à justiça. A história do acesso à justiça é a história de quem pensa e influencia as mudanças na estrutu$\mathrm{ra}$, isto é, de quem tem poder perante o Estado. De um lado, é uma história contada dos dominantes para os dominados e dominadas. São, neste sentido, precisas as palavras de Abel (1985: 598): legal aid is a social reform that begins with the solution - lawyers - and then looks for problems that it might solve. De outro lado, é uma história que os países centrais desenvolvidos contam para os países da periferia do sistema mundo. Como afirma Blakenburg (2002), a história da assistência jurídica é a história de estados de bem-estar generosos e de profissões jurídicas poderosas.

17 Santos 2007a defende que uma concepção pós-abissal tem como condição a co-presença radical, isto é, a presença e visibilidade simultânea dos dois lados da linha abissal que separa violência/apropriação da regulação/emancipação.
Essa maneira de contar a história reproduz-se na reflexão académica e nos critérios de escolha de casos para estudos históricos e $\operatorname{comparados}^{18}$ do acesso à justiça, em geral, e da assistência jurídica, em particular. Num estudo comparado sobre a evolução da assistência jurídica, Blankenburg (2002:112), por exemplo, justifica a não escolha de países latino-americanos, africanos e asiáticos como casos, por estes ainda ocuparem uma espécie de pré-história da assistência jurídica, dada a inexistência de cobertura por parte de um Estado-providência:

Our multi-country comparison sets out to compare only countries which were known to have developed an effective legal aid infrastructure for a wide array of problems, not just criminal defense. This implies that comparison is restricted to the rich countries around the world. In some countries of former British Commonwealth like India or Bangladesh, we find admirable lawyer initiatives. Likewise we find clinics in South Africa and at Latin America universities encouraged by development programs. Lacking a welfare state environment, however, they remain isolated initiatives, sponsored by reform-minded groups, often from rich countries. As one would predict, without a welfare state covering basic poverty one does not find a developed legal aid infrastructure.

O acesso à justiça que conta está profundamente influenciado pelo que Guha (2002) denominou estatismo. De acordo com Guha (2002) o estatismo aparece como uma ideologia que retira o poder de escolha dos sujeitos da história. Nesse sentido, os acontecimentos considerados

18 Basta verificar a escolha de estudos de caso do Projeto Florença. Ver também Regan, et al. (orgs.), 2002. 
historicamente dignos não procuram fazer correspondência com $\circ$ valor dignidade daqueles e daquelas que pensam e fazem a história. $O$ estatismo implica a defesa e a aceitação da ordem estabelecida, na medida em que transforma toda a reflexão sobre o curso da história numa genealogia do sistema político, social e dos valores vigentes. Esta visão contamina igualmente aos oponentes da ordem vigente, uma vez que a oposição procura substituir uma totalidade por outra, o poder vigente versus outro sonho de poder. Se o acesso à justiça é um importante indicador do carácter democrático dos estados, como se costuma dizer, o valor de democracia e o valor igualdade considerados dignos de integrarem a história do acesso à justiça corresponde à influência e ao poder daqueles que tiveram poder para transformar determinadas propostas de reforma em acontecimentos históricos.

Em raríssimas ocasiões esses acontecimentos corresponderam aos valores e às expectativas daqueles e daquelas a quem as reformas de acesso à justiça têm-se dirigido. Assinalo, neste âmbito, duas observações. A primeira é o fato de os acontecimentos históricos do acesso à justiça terem como centro o Estado, ignorando que em grande parte do mundo a história do acesso à justiça tem as suas portas abertas pelo pluralismo jurídico, convivendo com e evoluindo a partir de formas de resistência que se podem considerar manifestações anárquicas de justiça informal. Estes acontecimentos foram deixados de fora de estudos históricos e comparados que simplificaram a história do acesso à justiça na trajetória da generosidade e escassez dos Estadoprovidências. A segunda observação é a influência que $o$ estatismo exerce nas visões competitivas sobre 0 acesso à justiça na atualidade. Sendo certo que a realidade é de incumprimento da promessa do acesso à justiça e de perda do poder das profissões jurídicas em face da construção de uma política económica da justiça, o espaço remanescente de debate acerca dos conceitos e dos modelos de acesso à justiça é geralmente um espaço de competição entre visões de diferentes profissões jurídicas, na tentativa de influenciar as decisões do Estado, uma competição entre diferentes sonhos profissionais de poder (Guha, 2002).

Noutra dimensão, a história das conquistas no âmbito do acesso à justiça é em regra canibalizada pela história das vitórias obtidas dentro dos tribunais. Para além do reforço do mito dos direitos, a equação emancipação social e tribunais não envolve a discussão do acesso à justiça, pressupõe-na. A luta judicial pelos direitos é um privilégio daqueles e daquelas cultural e economicamente equipados para a batalha judicial, como refere Epp (1998), é necessário uma estrutura de apoio para a mobilização do direito nos tribunais: but cases do not arrive in supreme courts as if by magic ... the process by which individuals make claims about their legal rights and pursue lawsuits to defend or develop those right is not in any simple way a direct response to opportunities provided by constitutional promises or judicial decisions, or to expect arising from popular culture. Legal mobilization also depends on resources, and resources for litigation depend on a support structure of rights-advocacy lawyers, rights advocacy organizations, and sources of financing. A ampliação do espaço discursivo através da utilização dos tribunais na luta pelos direitos só é um argumento a favor da legitimidade democrática dos tribunais se estiver baseado na evidência de que é ampla a possibilidade de aceder aos tribunais, o que é uma falácia.

Por outro lado, o campo de enunciação do direito pelos tribunais é um clube pri- 
vativo, a emancipação social pedida nos tribunais e/ou concedida por eles, ainda que seja em nome de todos e todas é enunciada apenas por aqueles e aquelas profissionalmente competentes e investidos de autoridade para fazê-lo. Esse poder de enunciação separa o regime de verdade (Foucault, 1999) do campo jurídico dos regimes de verdade da ação social. Ainda que estejamos diante de advogados populares/de causas, o facto é que a atuação profissional que promove a mudança social o faz num papel que reforça a autoridade do campo jurídico e a separação entre o conflito jurídico e o conflito social.

A concorrência pelo monopólio do acesso aos meios jurídicos herdados do passado contribui para fundamentar a cisão social entre profanos e profissionais favorecendo o trabalho contínuo de racionalização próprio para aumentar cada vez mais o desvio entre os veredictos armados do direito e as instituições ingênuas da equidade e para fazer com que o sistema das normas jurídicas apareça aos que $\circ$ impõem e mesmo, em maior ou menos medidas, ao que ele estão sujeitos, como totalmente independente das relações de força que ele sanciona e consagra (Bourdieu, 1989:212).

Como já tive ocasião de defender, a história de emancipação social pelos tribunais padece do afunilamento da posição institucional do judiciário. $O$ outro lado da sobrevalorização da centralidade dos tribunais é a opacidade de uma discussão sobre o papel constitutivo do direito. A discussão do papel constitutivo do direito adequa-se uma realidade pós-moderna de reivindicações de direitos, à medida em descentra o direito e o poder do Estado. Estou de acordo com Merry
(1994:14-15) quando argumenta que uma das mais interessantes maneiras de pensar a contribuição cultural do direito para os projetos emancipatórios está na análise da resistência. Muito embora a análise da resistência assente numa microssociologia que se mostra pessimista em relação a grandes teorias de emancipação social, especialmente com o colapso das pretensões de justiça social em favor do capitalismo e de um consenso hegemônico neoliberal acerca de um determinado conteúdo da democracia, dos direitos humanos e do estado de direito, a esperança de mudança social pode assumir uma outra escala, de onde emergem micronarrativas de resistência.

Esta mudança implica uma conversão da noção de resistência, antes associada à consciência e levantes coletivos, para formas mais subtis, o que corresponde a um mundo pós-foucaltiano em que $\circ$ poder é capilar e não visível. É a característica sub-reptícia do poder que confere maior importância aos atos de resistência. Esta leitura da resistência não se pode exaurir numa abordagem contenciosa do conflito enquanto disputa contra o Estado. Tratase de uma malha complexa de poder e contra-poder em que a relação com o Estado é ambígua. Espera-se contrapor a violência do Estado da mesma maneira que se espera que o Estado se contraponha às formas de violência difusas. Nesse sentido, salienta Merry (1994), fala-se de resistência contra o direito, resistência através do direito, resistência que redefine o significado do direito, exercidas por movimentos sociais em momentos de confronto ou de negociação política ou, ainda, por pessoas comuns na condução do seu dia-a-dia.

A luta pelo acesso à justiça realiza assim uma tarefa arqueológica e geológica (Santos, 2007b). A dimensão arqueológica identifica as resistências, as 
manifestações do poder, a repressão do Estado, os momentos de confronto e de negociação como parte da construção política de acesso à justiça, recusando o valor histórico de uma narrativa exclusiva dos momentos de expansão do Estado e do papel dos profissionais protagonistas desta expansão. A dimensão geológica faz a prospeção da estrutura de apoio das causas sociais e a gestão dos recursos disponíveis, nesta avaliação geológica, o direito do Estado é um artefacto cultural à disposição da luta social. A mudança do Estado não tem por objetivo substituir - poder estatal por um sonho de poder equivalente com outros titulares. Por essa razão, a escala de ação do acesso à justiça dá tanto valor aos direitos como política, dimensão macroestrutural, como à infrapolítica (Scott, 2000) dos direitos, procurando estabelecer o diálogo entre os diversos atores e as diferentes escalas de resistência.

\section{CONCLUSÃO}

O direito e a justiça como promessas e o acesso como resposta mantêm-se acomodados numa modesta fórmula em que mais acesso associado a mais direito equivale a mais justiça. Falar de acesso à justiça neste sentido, seria, não só simples, mas também simplista, permitindo formular o que denomino estratégia de acumulação entre acesso, direito e justiça: se faz falta no acesso deve ser correspondido, preferencialmente em abundância, pelo direito e pela justiça.

A estratégia de acumulação converte o direito e a justiça em duas faces de uma mesma moeda que partilham uma única fonte de legitimidade, o Estado. A justiça rever-se-ia como justiça efetiva enquanto justiça oficial do Estado, e o direito rever-se-ia como justo enquanto garantia efetiva de direito de acesso. As oportu- nidades de acesso à justiça, em seus diferentes desdobramentos, passam a ser consideradas como indicadores centrais da democratização das comunidades políticas, atestando o comprometimento do Estado com a igualdade e com o bem-estar dos cidadãos. Para a sociologia do direito e dos tribunais, o campo de trabalho aparece claramente delimitado no estudo das deficiências e das fragilidades do direito e dos sistemas de justiça, bem como na discussão das alternativas que asseguram 0 acesso. A este propósito, a estratégia de acumulação contribui para um estreitamento discursivo do acesso à justiça. A crítica do direito e do funcionamento da ordem jurídica é absorvida no âmbito de uma engenharia social de reconstrução de sistemas mais acessíveis.

Numa proposição direta: quanto mais acesso à justiça, melhor direito; quanto mais se conhece dos obstáculos que se colocam ao acesso à justiça, de mais conhecimento se dispõe para aperfeiçoar a produção e a reprodução do direito. Numa espiral sem fim, 0 discurso do acesso à justiça debate-se entre a exposição das fraquezas e dos obstáculos do sistema de justiça e a discussão de respostas para o seu fortalecimento. Enquanto as soluções e políticas de acesso à justiça estão permanentemente submetidas ao escrutínio de um sistema de direitos que se reproduz como sistema de poder e opressão, a crítica ao direito é disciplinada através das reformas e das soluções para a construção de uma justiça acessível. A experiência de acesso à justiça é, assim, deslocada do presente. A atualidade do discurso de acesso à justiça é a de uma proposta que fracassou no passado, a bordo da pretensão de construção de um Estado-providência, e de um objetivo a alcançar no futuro, em consonância com - progresso civilizacional do direito como meio exclusivo de emancipação social. 
Entre a transgressão das denúncias das faltas do direito e a promessa do progresso do direito e pelo direito como emancipação, o acesso à justiça inscreve-se no âmbito de uma hegemonia discursiva da falta de acesso à justiça. Se a desigualdade de acesso ao direito e à justiça como promoção é inversamente proporcional à desigualdade de acesso ao direito e à justiça como repressão, isto é, quem mais sofre o impacto da repressão do direito é quem menos aproveita da promoção do direito como bem-estar, falar de acesso à justiça e de igualdade perante a lei é afirmar os termos da sua negação. Reside aqui um segundo aspeto da simplicidade de abordagem do tema do acesso à justiça. Em sociedades em que o reforço de utilização do direito como repressão não é equivalente ao esforço de promoção do direito como bem-estar social, não se fala de acesso à justiça, mas sim da falta de acesso à justiça. Tanto maior o impacto transgressivo da denúncia da falta de acesso, maiores as expectativas quanto às promessas de emancipação social do direito e pelo uso do direito.

Contraditoriamente, se o sentido atual do acesso à justiça é a sua ausência, exige que seja feita uma opção entre a transgressão e a promessa. Caso contrário, as denúncias presentes da falta de acesso ver-se-iam facilmente deglutidas e distendidas num horizonte de aperfeiçoamento infinito do direito e da democratização dos estados, perdendo a sua atualidade. Se o discurso do acesso à justiça está encarcerado numa estratégia de acumulação futura entre acesso, direito e justiça, o discurso da falta de acesso à justiça é presente e separa os termos da equação: a reivindicação de mais justiça ressalta da evidência de menos acesso e menos direito. Opera-se uma separação entre oportunidades oferecidas pelo sistema jurídico e judiciário e os resultados al- cançados, o que consequentemente compromete a legitimidade do Estado, se os direitos de acesso e o acesso aos direitos não são efetivos, a justiça não é justa.

Se é certo que a evidência da falta de acesso à justiça apela para sua importância e necessidade, a polarização argumentativa entre a defesa do acesso à justiça e a afirmação da falta de acesso à justiça não se resolve com a escolha de um dos dois lados. A defesa do acesso à justiça enquanto progresso da justiça e do direito do Estado extenua a crítica na medida em que ela é integrada no movimento de aperfeiçoamento e de ampliação do reconhecimento pelo direito. A denúncia da falta de acesso à justiça enquanto componente de um sistema jurídico estatal excludente e repressivo, por sua vez, retira o significado das reformas e das políticas de acesso à justiça, ao demonstrar a sua ineficácia.

E se as oportunidades de acesso à justiça existentes, ainda que limitadas, desembocarem em resultados socialmente justos, ainda que pontuais? É possível a simultaneidade da promessa e da transgressão? A promessa de acesso ao direito e à justiça coabitaria com a crítica ao modo de reprodução do direito do Estado? É possível apostar na transgressão para a reformulação das promessas de acesso à justiça?

A meu ver o impacto da promessa e o potencial da transgressão das medidas de acesso à justiça têm que ser investigadas a partir do que foi invalidado como experiência histórica, seja a trajetória dos sistemas de acesso à justiça dos países periféricos, sejam as experiências de acesso à justiça daqueles e daquelas para as quais a ideia de acesso como assistência social foi pensada, as populações pobres. As condições políticas e culturais de produção deste texto reivindicam assim a noção de co-apren- 
dizagem entre $\circ$ Norte e $\circ$ Sul global ${ }^{19}$. Neste ponto, ergue-se uma inversão, o Sul global, relegado a uma posição de atraso face à linha evolutiva da história universal, emerge na condição pioneira de antever o futuro do Norte global. Basta pensar que são as sociedades do Sul as primeiras a sentirem os efeitos negativos das forças históricas mundiais do capitalismo e do imperialismo (Comaroff e Comaroff, 2010). No que toca ao acesso à justiça, está-se ainda diante de outro Sul em condições de ocupar a dianteira no intercâmbio das lições de antagonismo à tendência neoliberalizante de restrição dos direitos (especialmente dos direitos sociais e económicos), as/os denegadas/ os no acesso aos direitos

\section{BIBLIOGRAFIA}

$A B E L$, Richard. 1985. Law without politics: legal aid under advanced capitalism. UCLA Law Review, 32, 474 .

BLACK, Donald. 1973. The mobilization of law. The Journal of Legal Studies, 2, 1: 125-1 49.

BLANKENBURG, Erhard. 2002. The lawyers' lobby and the welafare state: the political economy of legal aid. Francis REAGAN et al. (org.). The transformation of legal aid. Oxford: Oxford University Press.

BOURDIEU, Pierre 1989. O poder simbólico. Rio de Janeiro: Bertrand.

CAPPELLETTI, Mauro; GARTH, Bryant 1988. O acesso à justiça. Porto Alegre: Sergio Antonio Fabris.

COMAROFF, Jean; COMAROFF, John. 2006. Law and disorder in postcolony. Chicago: The University of Chicago Press.

CHAKRABARTY, D. 2000. Provincializing Europe: Postcolonial Thought and Historical Difference. Princeton: Princeton University Press.

19 A ideia de co-aprendizagem inspira-se na proposta de Boaventura de Sousa Santos (2002a:342): aprender que existe um sul, aprender a ir para o sul, aprender a partir do sul e com o sul.
EPSTEIN, Lee; KNIGHT, Jack 1996. On the judicial supremacy. Law and Society Review, 30, 1: 87-120.

EPP, Charles R. 1998. The rights revolution: lawyers, activists and supreme court in comparative perspective. Chicago: The University of Chicago Press.

FOUCAULT, Michel. 1999. A verdade e as formas jurídicas. Rio de Janeiro: Nau Editora.

GISNBURG, Tom; KAGAN, Robert. 2005. Institutions and public law. Comparative Approachs. New York: Peter Lang.

GUARNIERI, Carlo; PEDERZOLI, Partrizia. 2002. From democracy to juristocracy? The power of judges: A comparative study of courts and democracy. Oxford: Oxford University Press.

GUHA, Ranahit. 2002. Las voces de la historia y otros estúdios subalternos. Barcelona: Crítica.

HANDLER, Joel F. 1992. Postmodernisms, protest and the new social movements. Law and Society Review, 26, 4: 697-730.

HIRSCHL, Ran 2004. Towards juristocracy: the origins and consequences of the new constitutionalism. Cambridge: Harvard UP.

MCCAN, Michael 2006. Legal mobilization and social reform movements. Notes on theory and lts application. Michael MCCAN (org.). Law and Social Movements. London: Ashgate.

MERRY, Sally 1994. Resistance and the cultural power of law. Law and Society Review, 29, 1: 11-26.

REGAN, Francis et al. 2002. Introduction. Francis REGAN et al. (org.) The transformation of legal aid. Comparative and historical studies. Oxford: Oxford University Press.

ROSENBERG, Gerald. 2008. The hollow hope. Can courts bring about social change? Chicago: The University of Chicago Press.

SANTOS, Boaventura de Sousa. 1990. O Estado e o direito na transição pós-moderna. Revista Crítica de Ciências Sociais, 30: 13-31.

SANTOS, Boaventura de Sousa. 1998a. Tempo, códigos barrocos e canonização. Revista Crítica de Ciências Sociais, 51:3-20. 
SANTOS, Boaventura de Sousa. 1999. A construção multicultural da igualdade e da diferença. Oficina do CES, 135. Coimbra: Centro de Estudos Sociais.

SANTOS, Boaventura de Sousa. 2002. A crítica da razão indolente. Contra o desperdício da experiência. Porto: Afrontamento. 2. ${ }^{a}$ ed.

SANTOS, Boaventura de Sousa. 2002b. Para uma sociologia das ausências e das emergências. Revista Crítica de Ciências Sociais, 63: 237-280.

SANTOS, Boaventura de Sousa. 2003. Poderá o direito ser emancipatório? Revista Crítica de Ciências Sociais, 65: 3-76.

SANTOS, Boaventura de Sousa. 2006. A gramática do tempo. São Paulo: Cortez Editora.

SANTOS, Boaventura de Sousa. 2007a. Para além do pensamento abissal: das linhas globais à ecologia de saberes. Revista Crítica de Ciências Sociais, 78: 3-46.

SANTOS, Boaventura de Sousa. 2007b. Sociología jurídica crítica. Madrid: Trotta.

SANTOS, Boaventura de Sousa. 2011. Para uma revolução democrática da Justiça. $3^{a}$ ed. São Paulo: Cortez.

SARAT, Austin; SCHEINGOLD, Stuart. 1998. Cause lawyering: political commitments and professional responsibilities. New York: Oxford University Press.

SARAT, Austin; SCHEINGOLD, Stuart. 2001. Cause lawyering and the state in a global era. New York: Oxford University Press.
SARAT, Austin; SCHEINGOLD, Stuart. 2005. The worlds cause lawyers make: structure and agency in legal practice. Stanford, CA: Stanford University Press.

SCHEINGOLD, Stuart A. 2007. The politics of rights. Lawyers, public policy and social change. Michigan: University of Michigan Press.

SCOTT, James. 2000. Los dominados y la arte de la resistencia. Discursos ocultos. Cidade do México: Era.

SECRETARIA DA REFORMA DO JUDICIÁRIO. 2006b. Juizados especiais cíveis: Estudo. Brasília: Ministério da Justiça.

SECRETARIA DA REFORMA DO JUDICIÁRIO. 2008. Relato de uma experiência: Programa Justiça comunitária do Distrito Federal. Brasília: Ministério da Justiça.

SHAPIRO, Martin. 1964. Law and politics in the Supreme Court: New approaches to political jurisprudence.New York: Free Press of Glencoe.

SWEET, Alec Stone. 2000. Governing with judges: constitutional politics in Europe. Oxford: Oxford University Press.

TROCHEV, Alexei. 2004. Less democracy, more courts: a puzzle of judicial review in Russia. Law and Society, 38, 3:513-548.

TATE, C. NEAL, Torbjörn. 1995. The Global Expansion of Judicial Power. New York: New York University Press. 